\title{
COVID-19 Infections and Mortality in Florida Counties: Roles of Race, Ethnicity, Segregation, and 2020 Election Results
}

\author{
Patrick Bernet $^{1}$ iD
}

Received: 26 April 2021 / Revised: 7 August 2021 / Accepted: 16 August 2021 / Published online: 17 September 2021

(c) W. Montague Cobb-NMA Health Institute 2021

\begin{abstract}
Purpose This study investigates the association of racial and ethnic composition, segregation, and 2020 presidential election voting results with COVID-19 infections and deaths in Florida counties.

Methods Florida county COVID-19 infection and death counts reported through March 2021 were supplemented with socioeconomic characteristics and 2020 presidential results to form the dataset employed in this ecological study. Poisson regression analysis measured the association of infection and mortality rates with county demographic and economic characteristics, then assessed the moderating role of county political preferences.

Results Counties with higher proportions of Black residents experience disproportionately higher COVID-19 infection and mortality rates. Disparities are further inflated in counties with larger Republican vote shares. That voting effect extends to Hispanic population proportions and segregation, both of which are associated with higher COVID-19 infection and mortality rates in more Republican-leaning counties.

Conclusions Communities challenged by pre-existing health disparities, segregation, and economic hardship before the pandemic bear disproportionate risk of COVID-19 infection and mortality. Factors associated with voter preference for the 2020 Republican presidential candidate compound those problems, worsening consequences for all county residents, suggesting deeper structural health challenges.
\end{abstract}

Keywords COVID-19 $\cdot$ Racial and ethnic disparities $\cdot$ Segregation $\cdot$ Political affiliation

\section{Introduction}

Through March 2021, Florida is one of the most-infected states, with $10 \%$ of residents having testing positive for COVID-19 [1]. That burden is not shared equally. Blacks and Hispanics comprise $41 \%$ of the population, but $51 \%$ of all infections and $46 \%$ of all hospitalizations since the start of the pandemic through March 2021. Hispanics are almost twice as likely as whites to become infected. National studies find county infection rates increase $1.2 \%$ and mortality rates by $1.5 \%$ for each $1 \%$ increase in population proportion Black or Hispanic [2, 3]. At the individual level, workers in healthcare, hospitality, social assistance, and other high-transmission-risk industries are more likely to become infected [4]. Black and Hispanic workers are more likely employed in

Patrick Bernet

Pbernet@outlook.com

1 Florida Atlantic University, 777 Glades Road, Boca Raton, FL 33431, USA such positions, elevating infection rates for the entire community when these high-risk industries geographically cluster. In addition to these factors, other COVID-19 studies have found higher infection and mortality rates associated with community-level poverty, overcrowding, segregation, and average age $[5,6]$. Counties with higher proportions of females and lower high school graduation rates also experienced higher transmission rates [7]. A neighborhood-level study of Miami finds economic disadvantage has a stronger influence on infection rates than either race or ethnicity [8].

Public health decisions in Florida are strongly centralized, with a Republican governor and legislator giving county health departments virtually no local autonomy [9]. Such uniformity means all counties simultaneously reopened schools, liberalized bar and restaurant safety precautions [10], and eliminated mask restrictions. At short time scales, studies find within-county autocorrelated infection rates from one week to the next [7]. Over the longer time scale, a similar pattern is revealed in a lack of movement among the counties. Plotting infections from January 2020 to 
September 2020 against those for the October 2020 to March 2021 span, the tightly clustered diagonal in Fig. 1 shows that counties with high initial infection rates continued to have proportionately higher rates. Whether viewed through a filter based on political preferences, race, or ethnicity (see technical appendix), counties infection rates vis-à-vis one another did not change. Such consistency highlights the importance of each counties' initial set of underlying determinants [11]. Looking at mortality rates over the same two time periods (Fig. 2) reveals the same general pattern but with all counties showing virtually no growth in deaths while infections doubled. This is likely related to the governor's August 2020 edict that made it more difficult to classify a death as COVID-19 related [12].

Though imbalances in Florida mirror nationwide patterns, the state comes to these outcomes in a unique way; as much the result of pre-existing disparities entering the pandemic, as a political environment that amplifies and accelerates its spread. The pandemic has been accompanied by extraordinary levels of political messaging [13-15]. With a president and governor ignoring personal protective precautions and forgoing government-imposed controls [16], multiple studies find these attitudes echoed in masking and distancing behaviors of Republican-leaning areas [17]. Republican and Democratic voters differed in knowledge about the pandemic, its risks, and adoption of protective behaviors that reduce its spread $[18,19]$. Internet searches for pandemic-relating terms were lower in areas with higher proportions of Republican voters [20]. Residents of Democratic-voting counties were more likely to comply with stay-at-home mandates, voluntarily self-quarantine, and eschew recreational mobility $[21,22]$. Online spending increased more in Democraticleaning counties when stay-at-home orders were instituted, consistent with calls for reducing non-essential travel and greater distancing [15]. Other studies link such mobility decisions to increased infection rates [7]. Taken together, these studies suggest a causation chain that starts with community political preference as a primary determinant of area mobility behaviors, which are, in turn, strongly related to infections.

Political orientation is also associated with health outcomes in general. Areas more supportive of Trump in 2016 experience higher mortality rates, shorter life expectancies, and worse levels of overall public health. Elevated rates of drug-, alcohol-, or suicide-related mortality, the so-called deaths of despair, are also found in these counties [23, 24]. Entering the pandemic, thusly, such counties were primed for worse outcomes from the elevated infection rates invited by the lax protective behaviors associated with political rhetoric. Despite national studies associating diminished Republican voter intentions with higher COVID-19 mortality rates through June 2020 [11, 25], Florida voter support for the GOP presidential candidate increased from $49 \%$ in 2016 to $51.2 \%$ in 2020 .

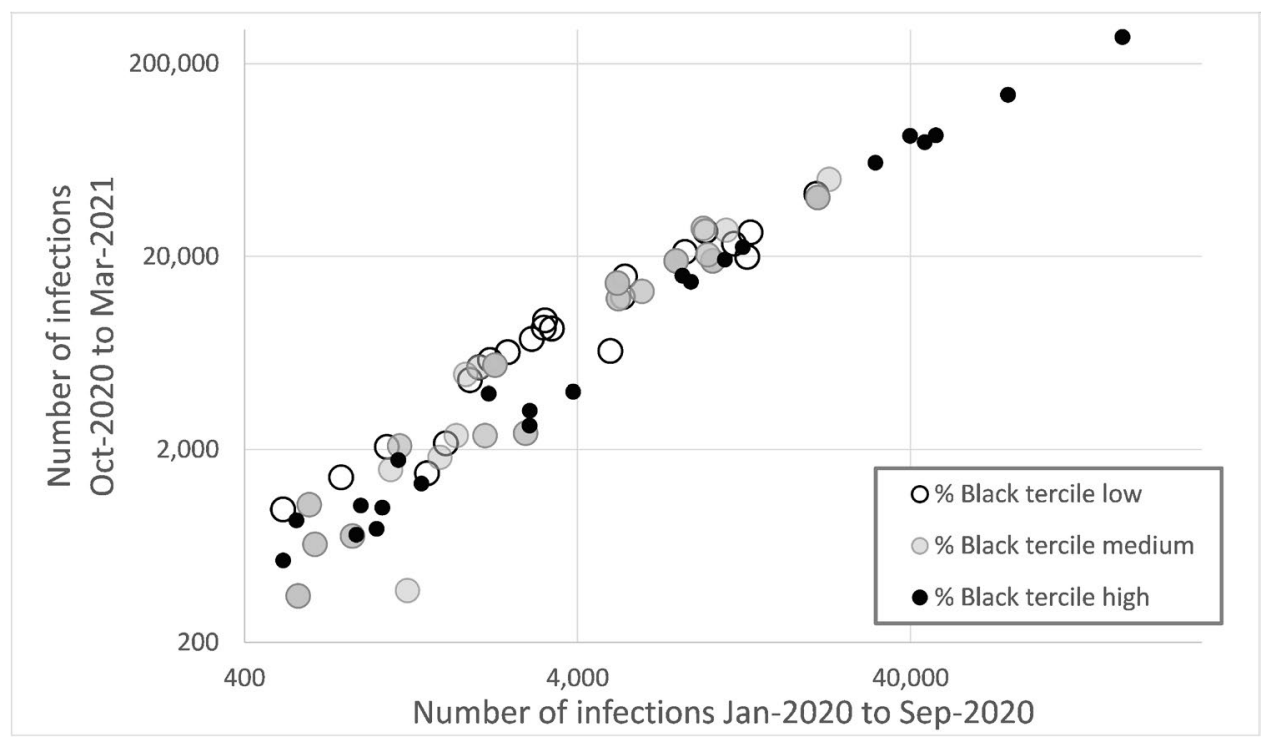

Fig. 1 COVID-19 infection rates in Jan 2020 to Sep 2020 compared to COVID-19 infection rates in Oct 2020 to Mar 2021; by \% (with $\%$ Black highlighted). COVID-19 death rates per 100,000 population through March 2021 are shown. Each data point represents one of Florida's 67 counties. Point placement is based on the number of infections per 100,000 (vertically) during Oct 2020 to Mar 2021 and number of infections per 100,000 (horizontally) during Jan 2020 to Sep 2020. Point shading indicates county proportion Black, with color transitioning from white for counties with the lowest \% Black to black for counties with the highest $\%$ Black. $N=67$. Data sources: American Community Survey, County Health Rankings, the Behavioral Risk Factor Surveillance System, the Florida Department of State, the Florida Department of Health, and the CDC 


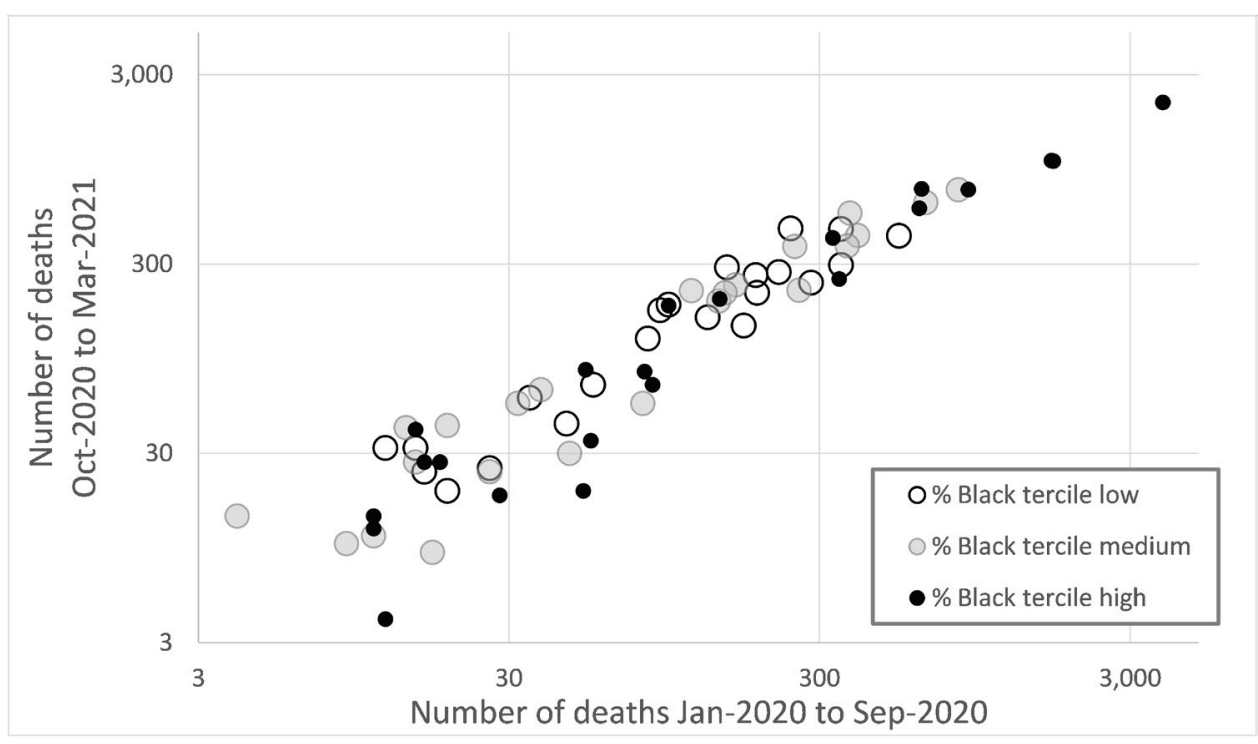

Fig. 2 COVID-19 mortality rates in Jan 2020 to Sep 2020 compared to COVID-19 mortality rates in Oct 2020 to Mar 2021; by \% (with $\%$ Black highlighted). COVID-19 death rates per 100,000 population through March 2021 are shown. Each data point represents one of Florida's 67 counties. Point placement is based on the number of deaths per 100,000 (vertically) during Oct 2020 to Mar 2021 and number of deaths per 100,000 (horizontally) during Jan 2020 to Sep

Pandemics exist only through interaction [14], and like any organism that thrives in environments least capable or willing to resist, it may flow fastest along fissures in the social fabric through which it transmits. In addition to the political divide, long-standing racial health disparities present another vulnerability for the pandemic to exploit. Black population proportions have been associated with higher COVID-19 infections in prior studies [26], showing increases as high as 389 additional cases per 100,000 between the 25th and 75th race percentiles of states [27]. At the individual level, Black patients are as much as 3.6 times more likely than whites to die from COVID-19 [28].

Even studies looking at pandemic spread using spatial models find such demographic characteristics, such as age, density, income, race, and health status, have an impact on infection rates [29-31]. By March 2021, the cumulative impact of multiple waves seen in the map in Fig. 3 reveals as many patterns as paradoxes. The concentration of high and medium infection rates in the northern part of the state, which is much more sparsely populated, confounds expectations that infections are more common in densely populated areas [29]. Contrary to studies showing diminished voter support for Republican candidates as pandemic outcomes worsened [25], these traditional Republican strongholds increased GOP vote shares between 2016 and 2020. The cluster in the middle of the state is centered in Osceola county with 11,506 infections per 100,000; over 2000 more infections per 100,000 than the metropolitan areas' Orlando
2020. Point shading indicates county proportion Black, with color transitioning from white for counties with the lowest $\%$ Black to black for counties with the highest \% Black. $N=67$. Data sources: American Community Survey, County Health Rankings, the Behavioral Risk Factor Surveillance System, the Florida Department of State, the Florida Department of Health, and the CDC

hub which is much more densely populated. Such patterns reinforce lessons learned from geospatial studies [30, 31] that physical proximity is just part of the social landscape through which pandemics spread.

Public health infrastructure is a key component in moderating pandemic spread, most notably through activities such as emergency preparedness and laboratory and contagious disease management. Like many public programs, resource allocations are set primarily though funding formulas [32, 33]. Formulas typically rely on population-level outcomes and health-associated characteristics, such as poverty levels, physician supply, age, race, and ethnicity [34]. In addition to mirroring the population-wide reach of many public health activities, the unit of analysis for funding decisions is generally the county, metropolitan area, or state level through which the activity is administered [35]. Not merely an exercise in budgeting, properly aligned formulas that allocate resources according to the most relevant community-level characteristics are an effective and equitable tool for distributing funding where it does the most good [36]. A grim reminder of the consequences of underfunding, Florida had been reducing public health expenditures in the 10 years leading up to the pandemic, leaving agencies woefully unprepared, under-staffed, and under-skilled [37].

Using county-level data from Florida, this study starts with a measurement of the association of disparities in COVID-19 infection rates with county racial, ethnic, and socioeconomic characteristics using a multivariate model 
Fig. 3 COVID-19 infection rates through Mar 2021 (shaded by infection rate tercile).

COVID-19 infection rates per 100,000 population through March 2021 are shown. Counties with the highest infection rates are shaded darkest, while those with in the lowest tercile are shaded light. $N=67$. Data sources: American Community Survey, County Health Rankings, the Behavioral Risk Factor Surveillance System, the Florida Department of State, the Florida Department of Health, and the CDC

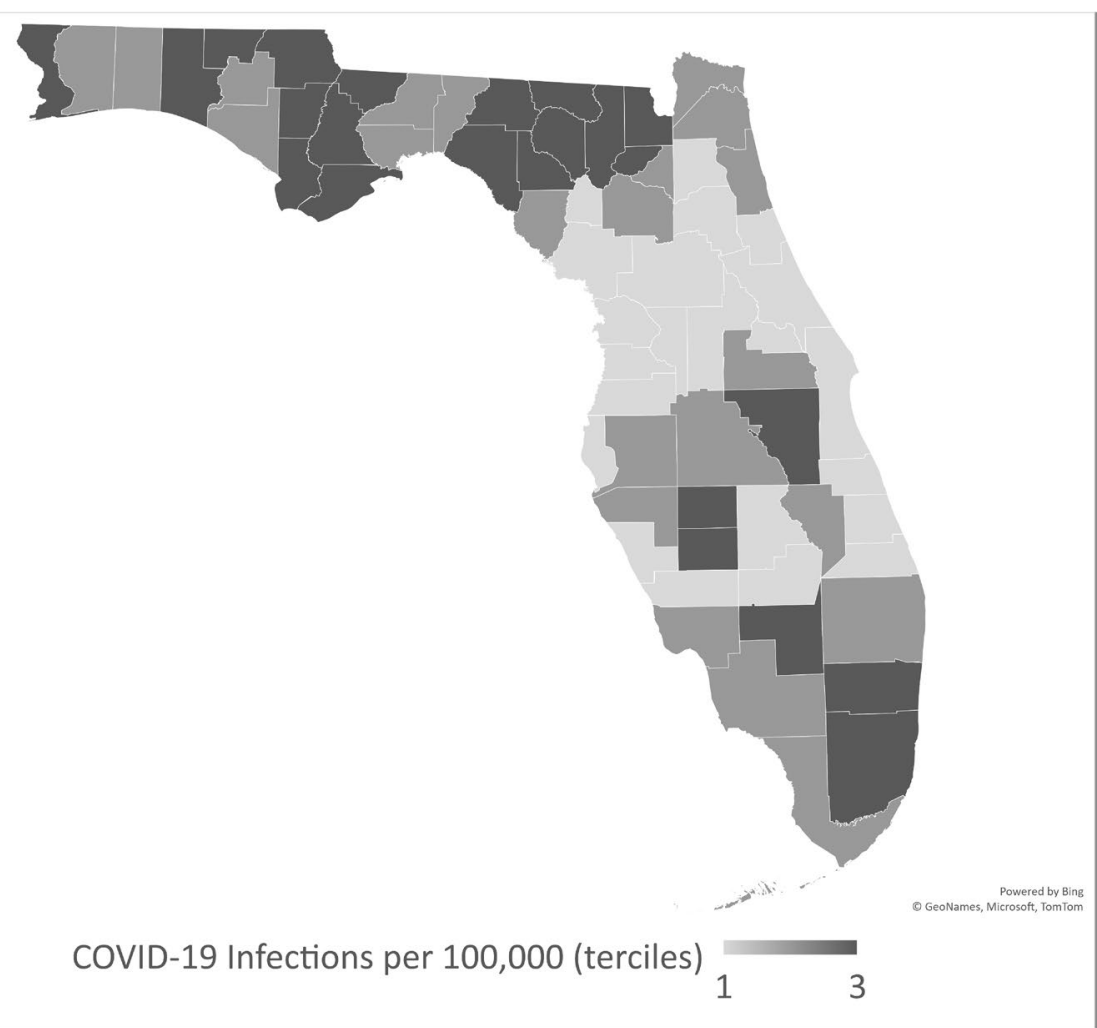

that includes this core set of determinants simultaneously. Residential segregation and political ideology are then added to the model to determine if these new variables improve the statistical strength of the models' accuracy and to measure the unique contributions of each independent variable to predicted infection rates. The same process is repeated for COVID-19 mortality rates to measure the statistical significance of each characteristic's influence on deaths.

\section{Methods}

\section{Data Sources and Measures}

Data on each of the 2,093,151 individual cases of COVID19 infection and mortality through March 2021 was retrieved from the Florida Department of Health [38], then summarized into pandemic-to-date case counts for each of Florida's 67 counties. To meaningfully compare counties of different size, infection and mortality rates are stated as rates per 100,000 residents using county population estimates from American Community Survey 5-year estimates (2014-2018) [39]. Set at the county-level, this ecological study is intended to identify characteristics of the entire community that are associated with average infection and mortality rates of the entire community. Though results of such studies are not applicable to the individual patient level, the county-level risk factors are relevant to policy discussions involving resource allocations between counties [35].

Prior pandemic research identifies a core set of county characteristics associated with disease spread and severity [26, 40-42], including population proportion over age 65 , population density, and poverty rates; all drawn from American Community Survey 5-year estimates. Core determinants also include proportions of high school graduates and proportions covered by health insurance [43].

In addition to core predictors, this study focuses on the potential influence of four county characteristics: race, ethnicity, segregation, and political preference. Population proportions Black non-Hispanic and Hispanic are derived from the American Community Survey. Residential segregation is measured with the nonwhite-white dissimilarity index, drawn from the same source. Based on the evenness of the racial composition of all county census tracts, it measures whether different groups are spread uniformly throughout the county or are geographically clustered. Finally, 2020 presidential election vote tallies were obtained from the Florida Department of State to identify the share of county votes received by the Republican candidate. All measures were standardized in terms of population proportions to facilitate comparisons. 


\section{Statistical Analysis}

This study focuses on infections and deaths per 100,000 residents. A summary overview of county characteristics starts the analysis, with $t$ tests highlighting differences by presidential political preferences. The influence of community characteristics on each COVID-19 outcome is then tested through two models. Model 1 assesses the influence of county proportions Black and Hispanic. Model 2 adds white-nonwhite segregation and the Republican share of 2020 presidential elections. With both dependent variables stated as rates per 100,000 , a generalized linear model with a Poisson distribution was employed. Analysis is not population weighted because the intent is to measure community characteristics and not to infer individual attributes. Tests for multicollinearity are conducted using the variance inflation factor to ensure interrelationships among independent variables do not introduce model distortions. IRB review was waived as all data was obtained from publicly available datasets. Analysis was conducted using Stata v16.1. The choice of analysis methods was informed by prior COVID-19 studies which employ the same race, age, segregation, and socioeconomic status indicators, drawn from the same data sources $[3,5,6]$.

\section{Results}

The range of characteristics across which Florida counties differ and the depth of those gaps is on display in Table 1. County infection rates average 9730 per 100,000 residents, with higher rates in the 12 counties won by the Democratic candidate in the 2020 presidential election $(10,239)$ than in those carried by the Republican candidate (9619), though the difference was not statistically significant at the 0.10 level in this simple two-dimensional comparison. Despite the lower infection rates, counties in which the Republican candidate won had higher mortality rates (199 per 100,000 residents, with a $p$ value of 0.005 ). Some of the core explanatory factors might hint at the cause of this role reversal, with higher proportions aged 65 and over (23\%), uninsured (16\%), or living in poverty (16\%) in Republican-won counties. The proportions Black (22\%) and Hispanic (26\%) in Democraticwon counties were about twice the portions in the 55 counties in which the Republican candidate won. Contrary to widely held assumptions, segregation is lower (32) in areas won by the Republican candidate ( $p$ value 0.10 ). (The technical appendix includes an expanded version of Table 1 that includes the core characteristics as well others, including provider supply, alternate measures of financial distress, and several health status indicators. That table is accompanied by a correlation matrix showing these other characteristics to be strongly associated with at least one of the variables already in the core model.)
Table 1 County characteristics and COVID-19 outcomes in Florida, as of March 2021 $(N=67)$

\begin{tabular}{|c|c|c|c|c|c|c|c|}
\hline & \multicolumn{2}{|c|}{ State total } & \multicolumn{2}{|c|}{ Democratic counties } & \multicolumn{2}{|c|}{ Republican counties } & \multirow[t]{2}{*}{$p$} \\
\hline & Mean & (S.D.) & Mean & (S.D.) & Mean & (S.D.) & \\
\hline Infections/100,000 & 9730 & (2296) & 10,239 & (2616) & 9619 & (2231) & 0.20 \\
\hline Deaths/100,000 & 190 & (69) & 144 & $(41)$ & 199 & $(70)$ & 0.01 \\
\hline \multicolumn{8}{|l|}{ Core characteristics } \\
\hline$\%$ Black & 14 & (9) & 22 & (13) & 12 & (7) & 0.00 \\
\hline$\%$ Hispanic & 15 & (13) & 26 & (19) & 12 & (10) & 0.00 \\
\hline Segregation nonwhite-white & 33 & (10) & 37 & (9) & 32 & (10) & 0.08 \\
\hline Republican vote $\% 2020$ & 63 & (14) & 41 & (6) & 68 & (9) & 0.00 \\
\hline$\%$ Aged 65 and over & 22 & (8) & 16 & (4) & 23 & (8) & 0.00 \\
\hline Population density (ln) & 5 & (1) & 7 & (1) & 5 & (1) & 0.00 \\
\hline$\%$ Uninsured & 15 & (3) & 14 & (2) & 16 & (3) & 0.13 \\
\hline$\%$ Poverty & 16 & (5) & 15 & (4) & 16 & (6) & 0.27 \\
\hline$\%$ High school graduate & 81 & (8) & 82 & $(10)$ & 81 & (8) & 0.41 \\
\hline Total population & 312 & $(493)$ & 1,015 & $(794)$ & 159 & $(186)$ & 0.00 \\
\hline$N$ & 72 & & 12 & & 55 & & \\
\hline
\end{tabular}

Standard deviations in parentheses. " $p$ " is two-sided $p$ value for difference between Democratic and Republican counties. "Democratic counties" are those counties won by Biden in 2020 presidential election. "Republican counties" are those counties won by Trump in 2020 presidential election. "S.D." is standard deviation. Data sources: American Community Survey, County Health Rankings, the Behavioral Risk Factor Surveillance System, the Florida Department of State, the Florida Department of Health, and the CDC 
Turning to regression models that consider the influence of multiple county characteristics simultaneously, the assessment of COVID-19 infections in Table 2 starts with model I1, pairing race and ethnicity with core determinants. Each percent increase in Black population share is associated with 50 more infections per 100,000 countywide, though there was no statistically significant association with Hispanic proportions. When Republican vote share was added in model I2, all four key determinants now register statistically significant influence on infection rates. Each percent increase in Black population share was associated with 138 more infections per 100,000 residents $(p<0.001)$. An additional 93 infections per 100,000 was associated with each percent increase in Hispanic proportions $(p<0.001)$. A oneunit increase in the white-nonwhite segregation index was associated with 44 more infections per 100,000 $(p<0.05)$.
Finally, each $1 \%$ increase in Republican vote share was associated with 111 additional infections per 100,000 $(p<0.001)$. Among the core variables for which the effects of race, ethnicity, segregation, and voter preferences are controlled, higher proportions of elderly are associated with lower infection rates across all models. Higher population densities are associated with lower infection rates, though the effect loses statistical significance when voter preferences are added in model I 2 .

Applying the same models to COVID-19 deaths per 100,000 brings slightly different results, with race and ethnicity showing no statistically significant association in the absence of voting considerations (model M1 in Table 2, showing $p$ values over 0.10 ). With voting effects added (model M-2), each percent increase in Black population share was associated with 4.7 additional deaths, and each

Table 2 County characteristics relating to COVID-19 infection and mortality rates in Florida, as of March $2021(N=67)$

\begin{tabular}{|c|c|c|c|c|c|c|c|c|}
\hline \multirow[t]{2}{*}{ Predictor } & \multicolumn{2}{|l|}{ I1 } & \multicolumn{2}{|l|}{$\mathrm{I} 2$} & \multicolumn{2}{|l|}{ M1 } & \multicolumn{2}{|l|}{ M2 } \\
\hline & $\begin{array}{l}\text { Infec- } \\
\text { tions } / 100,000\end{array}$ & $(95 \% \mathrm{CI})$ & $\begin{array}{l}\text { Infec- } \\
\text { tions } / 100,000\end{array}$ & $(95 \% \mathrm{CI})$ & $\begin{array}{l}\text { Mortal- } \\
\text { ity/100,000 }\end{array}$ & $(95 \% \mathrm{CI})$ & $\begin{array}{l}\text { Mortal- } \\
\text { ity/100,000 }\end{array}$ & $(95 \% \mathrm{CI})$ \\
\hline $\begin{array}{l}\% \text { Black } \\
\text { non-His- } \\
\text { panic }^{\mathrm{a}}\end{array}$ & $49.87 *$ & $(5.18,94.56)$ & $138.40 * * *$ & $(70.55,206.25)$ & -0.003 & $\begin{array}{c}(-0.44 \\
1.44)\end{array}$ & $4.6806^{* * *}$ & $(2.86,6.50)$ \\
\hline $\begin{array}{l}\% \text { Hispanic } \\
\left(\text { all races) }{ }^{\mathrm{a}}\right.\end{array}$ & 64.92 & $(-6.92,136.76)$ & $92.63 * * *$ & $(40.49,144.77)$ & -0.10 & $\begin{array}{c}(-1.42 \\
1.21)\end{array}$ & $1.76^{* *}$ & $(0.56,2.96)$ \\
\hline $\begin{array}{l}\text { Segregation } \\
\text { nonwhite/ } \\
\text { white }\end{array}$ & & & $44.15^{*}$ & $(2.80,85.50)$ & & & -0.48 & $\begin{array}{c}(-1.93 \\
0.97)\end{array}$ \\
\hline $\begin{array}{l}\text { Republican } \\
\% \text { of } 2020 \\
\text { presiden- } \\
\text { tial vote }\end{array}$ & & & $111.21 * * *$ & $(58.97,163.45)$ & & & $5.21 * * *$ & $(3.88,6.53)$ \\
\hline $\begin{array}{c}\% \text { Aged } 65 \\
\text { and over }\end{array}$ & $-82.06^{* *}$ & $(-133.18,-30.93)$ & $-92.84 * * *$ & $(-133.23,-52.46)$ & $2.77 * *$ & $(0.84,4.70)$ & $4.07 * * *$ & $(1.68,6.45)$ \\
\hline $\begin{array}{l}\text { Population } \\
\text { density/ } \\
\text { square } \\
\text { mile (ln) }\end{array}$ & $-730.46^{* * *}$ & $(-1088,-372)$ & -237.90 & $(-554.75,78.95)$ & -3.11 & $\begin{array}{c}(-17.29 \\
11.06)\end{array}$ & $24.45^{* * * *}$ & $\begin{array}{c}(12.72, \\
36.18)\end{array}$ \\
\hline $\begin{array}{l}\% \text { Unin- } \\
\text { sured }\end{array}$ & -153.60 & $(-410.57,103.38)$ & -144.64 & $(-369.34,80.06)$ & -3.88 & $\begin{array}{c}(-11.09 \\
3.33)\end{array}$ & -2.81 & $\begin{array}{c}(-8.65 \\
3.04)\end{array}$ \\
\hline $\begin{array}{l}\% \text { Living in } \\
\text { poverty }\end{array}$ & 47.98 & $(-55.78,151.74)$ & -14.21 & $(-102.89,74.47)$ & $7.21 *$ & $\begin{array}{c}(0.75, \\
13.67)\end{array}$ & $4.72 *$ & $(1.03,8.40)$ \\
\hline $\begin{array}{l}\% \text { High } \\
\text { school } \\
\text { graduate }\end{array}$ & 14.00 & $(-46.93,74.93)$ & 10.21 & $(-44.84,65.25)$ & 0.66 & $\begin{array}{c}(-1.73, \\
3.05)\end{array}$ & 0.70 & $\begin{array}{c}(-0.80 \\
2.20)\end{array}$ \\
\hline
\end{tabular}

Coefficients represent the change in the number of infections per 100,000 residents for models I1 and I 2 for each $1 \%$ change in the independent variable. Coefficients represent the change in the number of deaths per 100,000 residents for models M1 and M2 for each $1 \%$ change in the independent variable

$C I$ confidence interval

$* p<0.05, * * p<0.01, * * * p<0.001$

${ }^{a}$ Not shown, interaction effects between race and ethnicity with both segregation and vote shares were generally statistically significant though small. Details are available in the technical appendix to keep the paper focused on the impact of key variables

Data sources: American Community Survey, County Health Rankings, the Behavioral Risk Factor Surveillance System, the Florida Department of State, the Florida Department of Health, and the CDC 
percent increase in Hispanic proportions was associated with 1.8 more deaths. Segregation shows no definitive association with county-level COVID-19 mortality rates, but each percent increase in Republican vote shares was associated with 5.2 additional deaths per 100,000 residents. Among the core determinants, higher proportions age 65 and over, higher population densities, and higher poverty rates are all associated with more deaths per 100,000 residents (in model M2). With all independent variables registering variance inflation factors below 10 , tests for multicollinearity find no significant evidence of the kind of interrelationships among county characteristics that can distort regression coefficients.

\section{Discussion}

Using a county-level analysis of COVID-19 infection and mortality rates in Florida, this study tests the potential impact of race, ethnicity, segregation, and 2020 presidential election vote tallies. Counties with higher proportions of Black residents had higher infection rates (model I1, Table 2). When study context is expanded further to include politics (model I2), the race effect increases threefold and its statistical significance is greatly amplified. In fact, the model accuracy improves $25 \%$ when voting effects are added, demonstrating the strength of association between politics and COVID-19 outcomes. The graph in Fig. 4A demonstrates this effect, showing each county
Fig. 4 A COVID-19 infection rates by $\%$ Black (with Republican vote $\%$ highlighted). B COVID-19 infection rates by $\%$ Hispanic (with Republican vote $\%$ highlighted). COVID19 infection rates per 100,000 population through March 2021 are shown. Each data point represents one of Florida's 67 counties. Point placement is based on the number of infections per 100,000 (vertically) and the population proportion Black or Hispanic (horizontally). Point shading indicates proportion of 2020 presidential election votes for Republican candidate, with color transitioning from white for counties with the lowest portion of Republican votes to black for counties with the highest portion of Republican votes. $N=67$. Data sources: American Community Survey, County Health Rankings, the Behavioral Risk Factor Surveillance System, the Florida Department of State, the Florida Department of Health, and the CDC

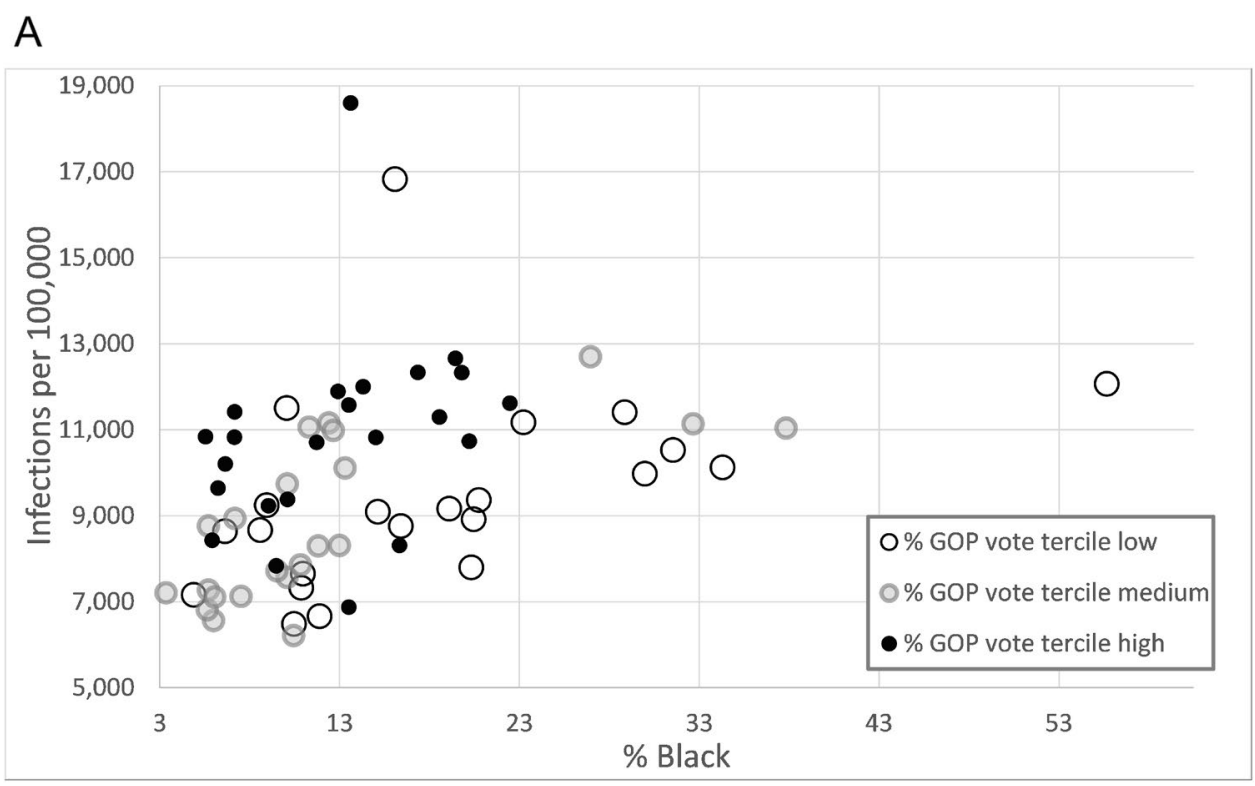

B

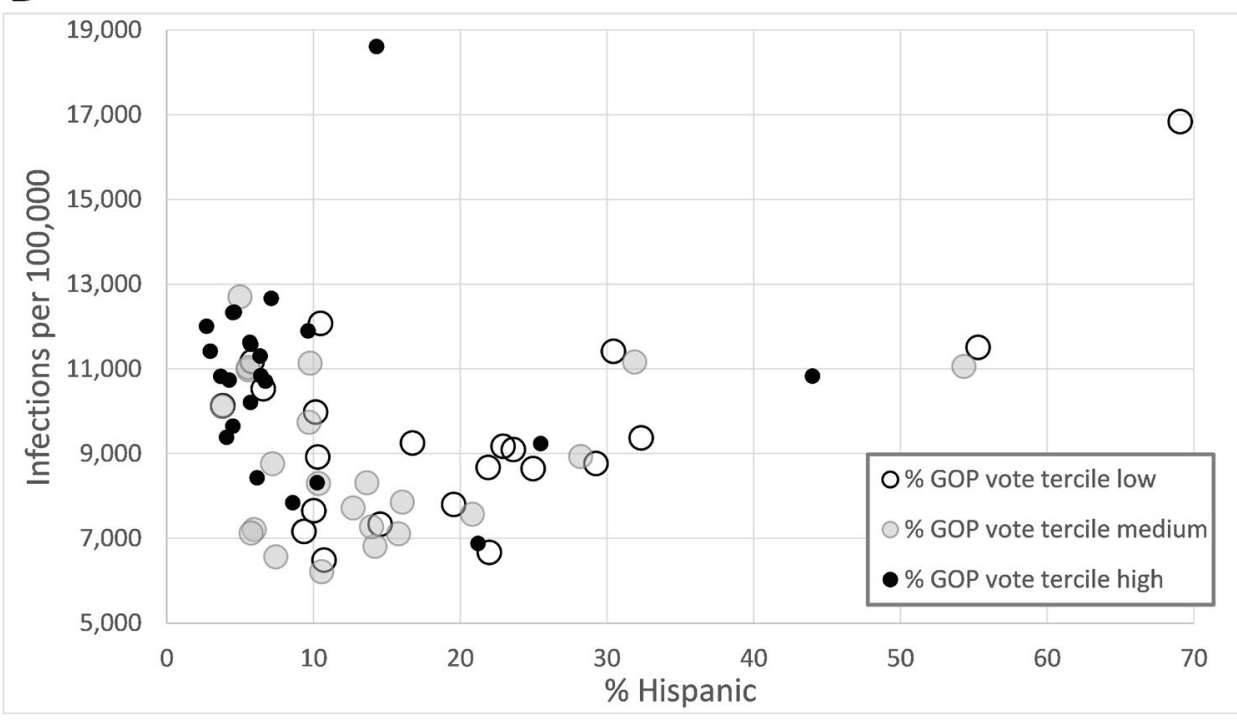


as a data point positioned based on its proportion of Black residents and infection rates per 100,000, with point shading varying from white (for lower Republican vote shares) to black (with higher vote shares). The upward slope shows counties with higher proportions of Black generally had higher infection rates. The concentration of black-shaded counties on the upper edge shows infection rates tend to be highest in counties with the strongest Republican proportions. Looking at vertical cylinders makes this clear. Many counties stack atop the state average Black proportion (14\%), with those voting more strongly Republican (black-shaded) atop the cylinder, with the higher infection rates.

Echoing race-politics interactions, Hispanic population proportions were related to infections only when Republican vote shares were considered. As can be seen in Fig. 4B, that association comes in a very different shape. A U-shaped distribution often indicates second-order effects, but politics offers a simpler explanation. At lower Hispanic proportions, infection rates seem to have more to do with Republican vote shares, as evidenced by the concentration of black-shaded county data points at the top of the vertical stack of counties with Hispanic population shares below $10 \%$. Viewed through this filter, the U-shape makes sense if the higher infection rates at lower Hispanic proportions are credited to political preferences, leaving a strong positive association between infections and Hispanic population share past the $10 \%$ level. This effect is a consequence of Florida's sociopolitical landscape, where those counties with the strongest Republican vote shares also have very small Hispanic proportions.

County political preference impacts on infection rates in two ways. First, higher Republican vote shares are associated directly with higher rates. Further, it clarifies the increased the size and statistical significance of race, ethnicity, and segregation coefficients. Essentially, outcomes credited to political leanings cannot be easily explained by race or ethnicity; especially as counties with high Republican support have very low portions Black or Hispanic (Table 1). Communities with higher proportions of Black and Hispanic residents already face health challenges [2, 5, 28]. And counties with higher proportions of Republican voters have been plagued by their own set of woes, such as the rise in "deaths of despair" $[23,24]$. This study demonstrates the compounded disproportionate impact that results when a disease is presented with multiple routes to pandemic growth.

The catalyst role played by Republican vote share is much more pronounced for COVID-19 mortality rates (Table 2). Neither race, nor ethnicity, nor segregation was associated with mortality until Republican vote share is considered. One possible link from political preferences to the race and ethnicity effects already reviewed is visually demonstrated in Fig. 5, where the upward slope shows the rising mortality rates with higher proportions of Republican votes. Along the curve, those counties with higher poverty rates (black shading) almost always had higher Republican vote shares and higher mortality rates. Counties with lowest poverty rates (white shading) were not among the highest Republican

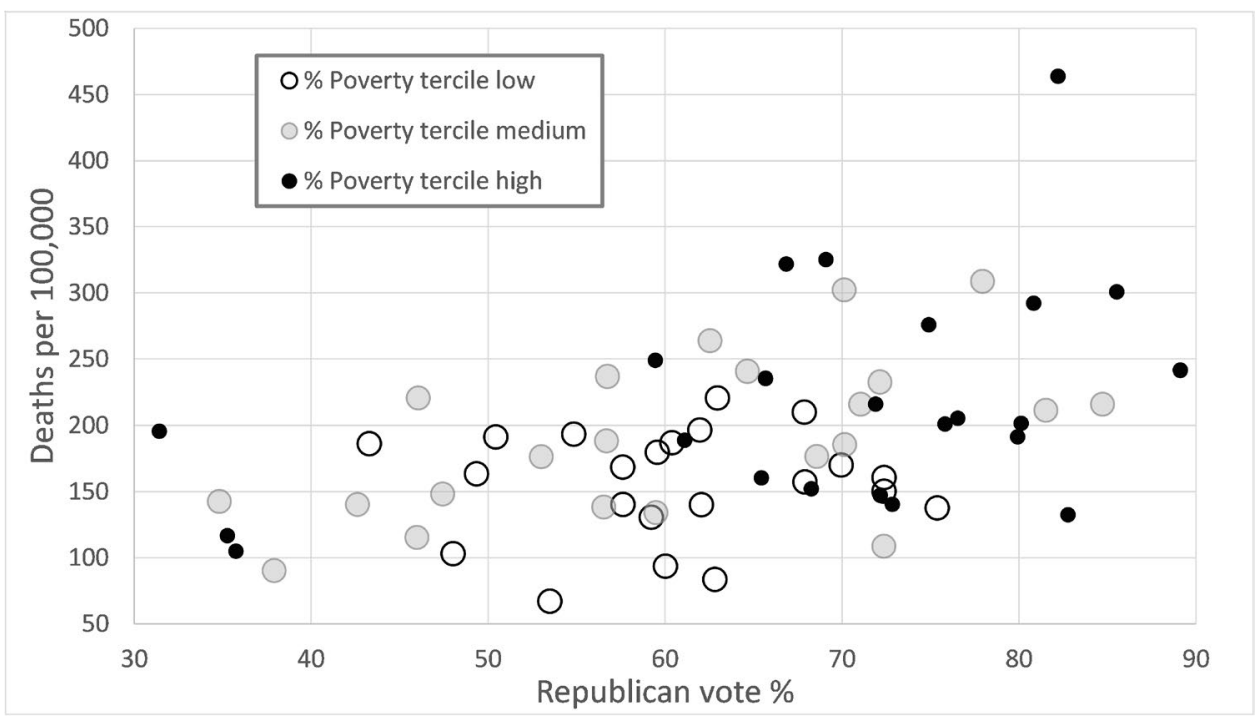

Fig. 5 COVID-19 mortality rates by \% Republican vote (with \% poverty highlighted). COVID-19 death rates per 100,000 population through March 2021 are shown. Each data point represents one of Florida's 67 counties. Point placement is based on the number of deaths per 100,000 (vertically) and the proportion voting Republican in the 2020 presidential election (horizontally). Point shading indicates county poverty rate, with color transitioning from white for counties with the lowest poverty rates to black for counties with the highest poverty rates. $N=67$. Data sources: American Community Survey, County Health Rankings, the Behavioral Risk Factor Surveillance System, the Florida Department of State, the Florida Department of Health, and the CDC 
vote shares and had lower mortality rates. Other studies have similarly linked poverty to pandemic outcomes [27], and this study shows the strength of its influence. It is not merely a reflection of economic disadvantages related to race and ethnicity. Indeed, it is a statistically significant predictor of mortality (model M1 in Table 2) even before voting effects are considered (model M2).

Study findings demonstrate myriad interactions among factors contributing to pandemic outcomes. Beyond reinforcing evidence linking poverty, race, ethnicity, and population density [5], this study is among the first to extend the link between partisan-related protective behaviors [15-18, $20,21]$ with COVID-19 infection and mortality. The political link introduces the possibility that pandemic-associated behaviors in Republican-leaning areas is a new expression of their deaths of despair crises [23, 42]. In linking community political preferences with infections, this study bridges research linking such partisan leanings to higher infection rates [7] and other research linking voter choices to infections [21, 22].

Findings from this study reinforce lessons learned in other studies of COVID-19 outcomes set in the USA. Numerous county and metropolitan level studies have identified a link between population proportions Black or Hispanic with higher COVID-19 infection and mortality rates [2, 3, 5-7]; several are even set in Florida [8, 16]. Similarly, many studies $[6,8,16,44]$ find higher poverty rates are associated with higher infection and mortality rates. Many studies have even linked higher voter preference for the 2020 Republican presidential candidate with higher infection and mortality rates $[3,11,25]$; some set specifically in Florida [16]. Findings discussed in this paper are based on a longer time scale than other similar papers. Showing that the influence of factors such as poverty, race, ethnicity and political preferences persist through March 2021, this paper adds conviction to earlier studies.

Florida is one of the most diverse states along many axes: elderly, foreign born, uninsured, Hispanic, poverty and political. Borrowing a metaphor for a state replete with them, Florida is often more a collection of adjacent gated communities than an integrated whole, with each difference a potential fault line through which pandemics thrive. While the depth of such fissures allowed this study to identify associated health consequences, their breadth illuminates the ways risks overlap, accelerate, dampen and interact with one another.

\section{Limitations}

Study findings should be understood in context of several limitations. First, this study is based on cases reported through March 2021 and subsequent waves might introduce new outcomes patterns. While the focus on a single state with Florida's unique sociopolitical environs requires careful generalization, is also reduces distortions introduced by inter-state differences in case counting and definitions of "COVID-19-related deaths" [45]. This study uses dissimilarity segregation measures, though other dimensions such as clustering might yield different findings [46]. The fluctuation of the coefficient on population density between statistical significance and insignificance suggests an interaction effect with either political preference or segregation that might benefit from future study. This study did not explore the wave dynamics of infection spikes rolling through time or spilling into neighboring counties. While future studies could take a closer look at such micro-level phenomenon, the absence of relative shifts among the counties already observed (Figs. 1 and 2) suggests that initial infection and mortality levels were based largely on how counties entered the pandemic and that strong centralized state control has given individual counties little opportunity to change their own destiny.

As an ecological level study, findings are appropriate for comparing counties among one another, but the same associations should not be inferred to the individual level. For instance, while county infection rates increase in proportion to the share of the voters favoring Republican candidates, this does not infer that individual Republican voters are at greater risk; only that collectively, the entire communityRepublicans, Democrats, and Independents alike-will have elevated infection rates. Similarly, the positive coefficient for Black population proportions does not necessarily mean Black individuals are more likely infected; only that everyone-Black, White, Asian, and others-living in the county is more likely infected. Even at that community level, studied characteristics might not be intrinsically related to outcomes, but merely surface measures of undercurrents. Statistical power and parsimony considerations preempted the inclusion of yet more such surface measures, such as mobility trends [7] and distancing [15], which are so tightly associated with political preferences $[21,22]$ that a much larger sample size would be required to determine whether such factors exert a unique influence or are simply manifestations of political preferences.

\section{Public Health Implications}

This study contributes to understanding COVID-19 by extending research showing lax adoption of preventative behaviors in Republican-leaning areas, showing these same counties experience higher infection and mortality rates [14-16, 18-21]. This study is also one of the first to demonstrate the association of county political preferences, race, segregation, and ethnicity, revealing an interaction effect that compounds problems for areas already challenged with pre-existing health disparities [23, 24, 40-42, 47]. Indeed, 
for mortality rates, ethnicity, and race influence was difficult to detect without political perspectives. Study findings can help inform policy decisions, identifying community characteristics associated with worse outcomes, allocating resources where they will do the most good, and customizing messaging to maintain protective practice compliance, including vaccination. In a hurricane state like Florida, the "perfect storm" analogy seems apt for a situation that saw election year messaging brought into a swing state where political affiliation itself was already related to pre-existing health challenges.

Data Availability To be made available upon request from the corresponding author.

Code Availability To be made available upon request from the corresponding author.

\section{Declarations}

Conflict of Interest The author declare no competing interests.

\section{References}

1. The COVID Tracking Project. Published 2020. Accessed November 9, 2020. https://covidtracking.com/

2. Khanijahani A. Racial, ethnic, and socioeconomic disparities in confirmed COVID-19 cases and deaths in the United States: a county-level analysis as of November 2020 null. 2021;26(1):2235. https://doi.org/10.1080/13557858.2020.1853067

3. Millett GA, Honermann B, Jones A, et al. White counties stand apart: the primacy of residential segregation in COVID-19 and HIV diagnoses. AIDS Patient Care STDS. 2020;34(10):417-24. https://doi.org/10.1089/apc.2020.0155.

4. Hawkins D. Differential occupational risk for COVID-19 and other infection exposure according to race and ethnicity. Am J Ind Med. 2020;63(9):817-20. https://doi.org/10.1002/ajim.23145.

5. Yang T-C, Choi SE, Sun F. COVID-19 cases in US counties: roles of racial/ethnic density and residential segregation. Ethn Health. 2021;26(1):11-21. https://doi.org/10.1080/13557858.2020.18300 36.

6. Yu Q, Salvador CE, Melani I, Berg MK, Neblett EW, Kitayama S. Racial residential segregation and economic disparity jointly exacerbate COVID-19 fatality in large American cities. Annals of the New York Academy of Sciences. 2021. https://doi.org/10.1111/ nyas. 14567.

7. Bhowmik T, Tirtha SD, Iraganaboina NC, Eluru N. A comprehensive analysis of COVID-19 transmission and mortality rates at the county level in the United States considering socio-demographics, health indicators, mobility trends and health care infrastructure attributes. PLoS ONE. 2021;16(4): e0249133. https://doi.org/10. 1371/journal.pone.0249133.

8. Palacio A, Tamariz L. Social Determinants of health mediate COVID-19 disparities in South Florida. J Gen Intern Med. 2021;36(2):472-7. https://doi.org/10.1007/s11606-020-06341-9.

9. Rozsa L, Brulliard K. On the covid-19 beat: rule enforcers seek cooperation but come ready to fine scofflaws. The Washington Post. Published online December 29, 2020. Accessed June 18, 2021. https://go-gale-com.ezproxy.fau.edu/ps/i.do?p=AONE\& $\mathrm{sw}=\mathrm{w} \& \mathrm{issn}=01908286 \& \mathrm{v}=2.1 \& \mathrm{it}=\mathrm{r} \& \mathrm{id}=\mathrm{GALE} \% 7 \mathrm{CA} 64$ $6938349 \&$ sid $=$ googleScholar\&linkaccess $=$ abs

10. Glaeser EL, Jin GZ, Leyden BT, Luca M. Learning from deregulation: the asymmetric impact of lockdown and reopening on risky behavior during COVID-19. National Bureau of Economic Research; 2020. https://doi.org/10.3386/w27650

11. Baccini L, Brodeur A, Weymouth S. The COVID-19 pandemic and the 2020 US presidential election. J Popul Econ. 2021;34(2):739-67. https://doi.org/10.1007/ s00148-020-00820-3.

12. Lu D. Other causes of death have surged as well: [Foreign Desk]. New York Times. https://login.ezproxy.fau.edu/login?url=https:// www.proquest.com/docview/2408436269? accountid $=10902$. Published June 2, 2020. Accessed 30 Jun 2021.

13. Grossman D. The unintended effects of place based programs: fertility and health effects of urban empowerment zones. J Health Econ. 2019;63:114-27. https://doi.org/10.1016/j.jhealeco.2018. 11.005 .

14. Barrios J, Hochberg Y. Risk perception through the lens of politics in the time of the COVID-19 pandemic. National Bureau of Economic Research; 2020:w27008. https://doi.org/10.3386/w27008

15. Painter M, Qiu T. Political beliefs affect compliance with COVID19 social distancing orders. SSRN Journal. Published online 2020. https://doi.org/10.2139/ssrn.3569098

16. Yano M. Covid-19 pandemic and politics: the cases of Florida and Ohio. Published online 2020. https://www.rieti.go.jp/en/index. html. Accessed 5 May 2021.

17. Katz J, Sanger-Katz M, Quealy K. A Detailed map of who is wearing masks in the U.S. New York Times (Online). Published July 17, 2020. https://login.ezproxy.fau.edu/login?url=https://www. proquest.com/docview/2424597136? accountid=10902. Accessed 1 Oct 2020.

18. Grossman G, Kim S, Rexer J, Thirumurthy H. Political partisanship influences behavioral responses to governors' recommendations for COVID-19 prevention in the United States. SSRN Journal. Published online 2020. https://doi.org/10.2139/ssrn.3578695

19. Allcott H, Boxell L, Conway J, Gentzkow M, Thaler M, Yang D. Polarization and public health: partisan differences in social distancing during the coronavirus pandemic. NBER Working Paper. 2020. Published online 2020. https://papers.ssrn.com/sol3/papers. cfm?abstract_id=3574415\#. Accessed 5 Jan 2021.

20. Jiang J, Chen E, Yan S, Lerman K, Ferrara E. Political polarization drives online conversations about COVID-19 in the United States. Human Behav and Emerg Tech. 2020;2(3):200-11. https:// doi.org/10.1002/hbe2.202.

21. Borgonovi F, Andrieu E. Bowling together by bowling alone: social capital and COVID-19. Soc Sci Med. Published online November 4, 2020:113501. https://doi.org/10.1016/j.socscimed. 2020.113501

22. Brzezinski A, Deiana G, Kecht V, Van Dijcke D. The covid19 pandemic: government vs. community action across the United States. Covid Economics: Vetted and Real-Time Papers. 2020;7:115-156.

23. Monnat S. Deaths of despair and support for Trump in the 2016 Presidential Election. Research Brief. Published online 2016.

24. Bilal U, Knapp EA, Cooper RS. Swing voting in the 2016 presidential election in counties where midlife mortality has been rising in white non-Hispanic Americans. Soc Sci Med. 2018;197:338. https://doi.org/10.1016/j.socscimed.2017.11.050.

25. Warshaw C, Vavreck L, Baxter-King R. Fatalities from COVID-19 are reducing Americans' support for Republicans at every level of federal office. Science Advances. 2020;6(44):eabd8564. https:// doi.org/10.1126/sciadv.abd8564

26. Desmet $\mathrm{K}$, Wacziarg R. Understanding spatial variation in COVID-19 across the United States. National Bureau of Economic Research; 2020. https://doi.org/10.3386/w27329 
27. Chambless L. Why do per capita COVID-19 case rates differ between U.S. states? medRxiv. Published online November 3, 2020:2020.10.16.20213892. https://doi.org/10.1101/2020.10.16. 20213892

28. Bassett MT, Chen JT, Krieger N. Variation in racial/ethnic disparities in COVID-19 mortality by age in the United States: a cross-sectional study. PLoS Med. 2020;17(10):e1003402. https:// doi.org/10.1371/journal.pmed.1003402.

29. Andersen LM, Harden SR, Sugg MM, Runkle JD, Lundquist TE. Analyzing the spatial determinants of local Covid-19 transmission in the United States. Sci Total Environ. 2021;754:142396. https:// doi.org/10.1016/j.scitotenv.2020.142396.

30. Iyanda AE, Boakye KA, Lu Y, Oppong JR. Racial/ethnic heterogeneity and rural-urban disparity of COVID-19 case fatality ratio in the USA: a negative binomial and GIS-based analysis. $J$ Racial and Ethnic Health Disparities. Published online February 26, 2021. https://doi.org/10.1007/s40615-021-01006-7

31. Iyanda AE, Adeleke R, Lu Y, et al. A retrospective cross-national examination of COVID-19 outbreak in 175 countries: a multiscale geographically weighted regression analysis (January 11-June 28, 2020). J Infect Public Health. 2020;13(10):1438-45. https://doi. org/10.1016/j.jiph.2020.07.006.

32. Jabine T, Louis T, Schirm A. Choosing the right formula: initial report.; 2001. https://doi.org/10.17226/10178

33. Ogden LL, Sellers K, Sammartino C, Buehler JW, Bernet PM. Funding formulas for public health allocations: federal and state strategies. J Public Health Manag Pract. 2012;18(4):309-16. https://doi.org/10.1097/PHH.0b013e3182431d8f.

34. Buehler JW, Holtgrave DR. Who gets how much: funding formulas in federal public health programs. J Public Health Manag Pract. 2007;13(2):151-5.

35. Buehler JW, Bernet PM, Ogden LL. Reference allocations and use of a disparity measure to inform the design of allocation funding formulas in public health programs. J Public Health Manag Pract. 2012;18(4):333-8. https://doi.org/10.1097/PHH.0b013 e3182431dc2.

36. Bekemeier B, Chen AL-T, Kawakyu N, Yang Y. Local public health resource allocation. Am J Prev Med 2013;45(6):769-775. https://doi.org/10.1016/j.amepre.2013.08.009

37. Recht LU Jason Dearen, The Associated Press, Hannah. Florida's cautionary tale: how gutting and muzzling public health fueled COVID fire. Kaiser Health News. Published August 24, 2020. Accessed December 2, 2020. https://khn. org/news/floridas-cautionary-tale-how-starving-and-muzzl ing-public-health-fueled-covid-fire/
38. CDC. Coronavirus Disease (COVID-19). Centers for Disease Control and Prevention. Published February 11, 2020. Accessed November 9, 2020. https://www.cdc.gov/coronavirus/2019-ncov/ index.html

39. US Census Bureau. American Community Survey (ACS). The United States Census Bureau. Accessed April 1, 2021. https:// www.census.gov/programs-surveys/acs

40. Sloan C, Chandrasekhar R, Mitchel E, Schaffner W, Lindegren ML. Socioeconomic disparities and influenza hospitalizations, Tennessee, USA. Emerg Infect Dis. 2015;21(9):1602-10. https:// doi.org/10.3201/eid2109.141861.

41. Placzek H, Madoff L. Effect of race/ethnicity and socioeconomic status on pandemic H1N1-related outcomes in Massachusetts. Am J Public Health. 2014;104(1):e31-8.

42. Bor J. Diverging life expectancies and voting patterns in the 2016 US Presidential Election. Am J Public Health. 2017;107(10):1560-2. https://doi.org/10.2105/AJPH.2017. 303945.

43. University of Wisconsin Population Health Institute. County health rankings. University of Wisconsin Population Health Institute Accessed April 1, 2021. https://www.countyhealthrankings. org/county-health-rankings-roadmaps

44. Bhowmik T, Eluru N. A comprehensive county level framework to identify factors affecting hospital capacity and predict future hospital demand. medRxiv. Published online February 25, 2021:2021.02.19.21252117. https://doi.org/10.1101/2021.02.19. 21252117

45. McCarthy T. US public increasingly skeptical of Covid-19 death toll, poll finds. the Guardian. http://www.theguardian.com/world/ 2020/jul/21/us-coronavirus-death-toll-public-opinion-poll-accur acy. Published July 21, 2020. Accessed November 9, 2020.

46. Bassolas A, Sousa S, Nicosia V. Diffusion segregation and the disproportionate incidence of COVID-19 in African American communities. J R Soc Interface. 2021;18(174):20200961.

47. Rodriguez JM. Health disparities, politics, and the maintenance of the status quo: a new theory of inequality. Soc Sci Med. 2018;200:36-43. https://doi.org/10.1016/j.socscimed.2018.01. 010.

Publisher's Note Springer Nature remains neutral with regard to jurisdictional claims in published maps and institutional affiliations. 